University of Nebraska - Lincoln

DigitalCommons@University of Nebraska - Lincoln

Faculty Publications, Department of Psychology

Psychology, Department of

3-2005

Epistasis among Presynaptic Serotonergic System Components

Scott F. Stoltenberg

sstoltenberg2@unl.edu

Follow this and additional works at: https://digitalcommons.unl.edu/psychfacpub

Part of the Psychiatry and Psychology Commons

Stoltenberg, Scott F., "Epistasis among Presynaptic Serotonergic System Components" (2005). Faculty Publications, Department of Psychology. 423.

https://digitalcommons.unl.edu/psychfacpub/423

This Article is brought to you for free and open access by the Psychology, Department of at DigitalCommons@University of Nebraska - Lincoln. It has been accepted for inclusion in Faculty Publications, Department of Psychology by an authorized administrator of DigitalCommons@University of Nebraska - Lincoln. 


\title{
Epistasis among Presynaptic Serotonergic System Components
}

\author{
Scott F. Stoltenberg \\ Department of Psychiatry, University of Michigan Addiction Research Center, Ann Arbor, Michigan \\ Present address (2004): Department of Psychology, Black Hills State University, Spearfish, South Dakota
}

\begin{abstract}
Epistatic interactions among regulatory components of the serotonin (5-HT) neurotransmitter system may be an important aspect of 5-HT function. Because 5-HT dysregulation is associated with several common psychiatric disorders, the potential for epistasis among genetic variants in the 5-HT transporter (SERT), 5- $\mathrm{HT}_{1 \mathrm{~B}}$ terminal autoreceptor and the $5-\mathrm{HT}_{1 \mathrm{~A}}$ somatodendritic autoreceptor should be examined. In this study, output from a dynamic minimal model of 5-HT function was compared to empirical results in the literature. Parameters representing extracellular 5-HT clearance rates (SERT), 5-HT release levels (5-HT $1 \mathrm{~B}$ ) and inhibitory thresholds (the amount of extracellular 5-HT above which cell firing is inhibited, an indication of $5-\mathrm{HT}_{1 \mathrm{~A}}$ autoreceptor sensitivity) were varied to simulate genetic deletion (i.e., knockout) of each component singly, and in combination. Simulated knockout effects on extracellular 5-HT level and presynaptic neural firing rates were in the same direction and of similar relative magnitude as studies in the literature. Epistasis among presynaptic components appears to be important in the 5-HT system's regulation of extracellular 5-HT levels, but not of firing rates.
\end{abstract}

Keywords: Dynamic systems, epistasis, knockout, serotonin, SERT, 5-HT1A, 5-HT1B.

\section{Introduction}

It is important to improve our understanding of how the serotonin (5-HT) system is controlled because it is involved in the etiology of common psychiatric disorders such as depression (Blier and de Montigny, 1998), obsessive compulsive disorder (Baumgarten and Grozdanovic, 1998), schizophrenia (Aghajanian and Marek, 2000) and alcoholism Heinz et al., 2001; Hill et al., 1999). It is likely that certain combinations of common genetic variants confer different risk profiles and treatment prognoses for their carriers than do other combinations and that such genegene interactions may be more important in common disorders than are main effects of any single gene (Moore, 2003). A more complete understanding of the relations among genetically varying system components in the regulation of 5-HT function that in- cludes epistasis has the potential to improve psychiatric treatment by providing a theoretical framework for genetically individualized therapy based on pharmacogenetic profiling (Lesch, 2002).

The terms physiological or mechanistic epistasis describe a situation wherein the effect on a phenotype of a particular allele at a locus depends on the allelic state of one or more other loci (Brodie, 2000). Such epistatic interactions are likely in traits with complex genetic architectures and blur the distinction between "major" and "minor" genetic effects because the effect of a given allele on a phenotype is not a property of that allele, but is context dependent (Templeton, 2000). Physiological epistasis does not appear to be rare, and in fact, in the genetic architecture of common human diseases, epistasis may be ubiquitous (Moore, 2003). Therefore, it is reasonable to seek evidence for epistasis in physiological systems 
where components interact; and the $5-\mathrm{HT}$ system is a good candidate system in which to seek evidence of epistasis because it is comprised of multiple, interactive components that vary genetically and because 5HT dysfunction is associated with risk for common psychiatric disorders (Veenstra-VanderWeele et al., 2000).

Experimental strategies that use lines of mice with genetic deletions (i.e., knockouts) have been employed to investigate the contribution of serotonin transporters (Gobbi et al., 2001; Mannoury la Cour et al., 2001), 5- $\mathrm{HT}_{1 \mathrm{~A}}$ somatodendritic (He et al., 2001; Knobelman et al., 2001a, b; Parsons et al., 2001; Richer et al., 2002) and $5-\mathrm{HT}_{1 \mathrm{~B}}$ terminal autoreceptors (de Groote et al., 2002; Evrard et al., 1999; Knobelman et al., 2001a, b; Malagie et al., 2002) to the regulation of 5 -HT function. Studies using in vivo microdialysis (de Groote et al., 2002; He et al., 2001; Knobelman et al., 2001a, b; Malagie et al., 2002; Parsons et al., 2001) and single unit cell recording Evrard et al., 1999; Gobbi et al., 2001; Mannoury la Cour et al., 2001; Richer et al., 2002) have provided valuable data on extracellular 5HT concentration and cell firing rates, respectively. Although there is evidence that the effects of each component may not be the same in different brain regions (Knobelman et al., 2001a, b; Malagie et al., 2002), it is clear that the 5-HT transporter (SERT) and the autoreceptors contribute to 5-HT regulation. Studying knockout mice has provided substantial suggestive evidence for epistatic effects on traits influenced by 5HT function when components are jointly examined by genetic deletion and/ or pharmacological manipulation (de Groote et al., 2002; Evrard et al., 1999; Gobbi et al., 2001; He et al., 2001; Knobelman et al., 2001a, b; Malagie et al., 2002; Murphy et al., 2001; Parsons et al., 2001).

A negative feedback framework is generally accepted to underlie the regulation of the 5-HT system (Aghajanian and Sanders-Bush, 2002); however, a systematic quantitative examination of such a model has not been carried out with computer simulation. In this study, I present a quantitative model of negative feedback regulation of presynaptic 5-HT function and compare simulation-generated results with extant empirical results from the literature. This model is not intended to simulate the function of single neuron; rather, it is a "top down" look at the regulation of the central 5-HT system. In a sense, this model may be considered a caricature of how genetically varying components in the 5-HT system may influence indices of 5-HT function. As with all caricatures, it is in- tended to capture the essence of the subject in broad strokes, not to replicate the subject in minute detail. Variables in the simulation modeled genetic deletion of SERT, somatodendritic $5-\mathrm{HT}_{1 \mathrm{~A}}$ and terminal $5-\mathrm{HT}_{1 \mathrm{~B}}$ autoreceptors. The simulation incorporates dynamic rules to adjust somatodendritic autoreceptor sensitivity and terminal autoreceptor mediated 5-HT release amounts. The purpose of this study, was to examine the general hypothesis that presynaptic 5-HT function is influenced by epistatic interactions among SERT and the somatodendritic $5-\mathrm{HT}_{1 \mathrm{~A}}$ and terminal $5-\mathrm{HT}_{1 \mathrm{~B}}$ autoreceptors. Comparing simulation results with microdialysis and single- unit recording results from the empirical literature should determine whether this interactive, dynamic, three-component model of presynaptic 5-HT control is sufficient to capture the dynamics of 5-HT regulation.

\section{Method}

\section{Software}

Because system dynamics models are well suited to analyze biological control systems (Gallaher, 1996) this model was implemented using Berkeley Madonna 8.0.1 (Zahnley, 2000); a commercially available simulation tool. The simulation was conducted by numerically solving differential equations. The code used to generate data is included in the Appendix 1.

\section{The Model}

Perhaps the most intuitive way to describe the model is by referring to the component parts and behavior of a single neuron. However, it should be kept in mind that for the present model the level of analysis is conceptualized as the central 5-HT system consisting of tens of thousands of neurons originating in the raphe nucleus and projecting to most brain areas (Baumgarten and Gothert, 1999).

Vesicular releases triggered by action potentials introduce serotonin into the extracellular compartment (see Figure 1). Aspects of serotonin release are determined by terminal (1B) and somatodendritic (1A) autoreceptors. Somatodendritic autoreceptors determine whether the system releases any serotonin (i.e., whether the system "fires") based on a comparison of the level of extracellular serotonin to an inhibitory threshold. If the level of extracellular serotonin exceeds the inhibitory threshold the somatodendritic autoreceptors inhibit system firing (i.e., no serotonin 
is released). Conversely, if the level of extracellular serotonin is below the inhibitory threshold the somatodendritic autoreceptors permit firing. Based on this firing decision the threshold is adjusted to either increase or decrease receptor sensitivity such that if the system has just fired, the threshold is decreased to make it less likely that the system will fire at the next time step; whereas if the system did not fire, the inhibitory threshold is increased to make firing more likely at the next time step. Genetic variation at the $5-\mathrm{HT}_{1 \mathrm{~A}}$ autoreceptor is assumed to affect the rate at which changes in sensitivity occur.

When the system fires, the amount of serotonin to be released into the extracellular compartment for that particular time step is determined by the terminal (1B) autoreceptor. For normal functioning, it is assumed that the terminal autoreceptor adjusts the release amount according to the level of serotonin in the extracellular compartment. That is, when extracellular serotonin levels are high, less serotonin is released, and when levels are low, more serotonin is released. Genetic variation at the $5-\mathrm{HT}_{1 \mathrm{~B}}$ autoreceptor is assumed to eliminate such responsiveness to the level of serotonin in the extracellular compartment so that level of serotonin released remains constant.

Serotonin flows out of the extracellular compartment by transporter mediated reuptake and by diffusion. Reuptake and diffusion are modeled to remove a proportion of the serotonin in the extracellular compartment at each time step. For normal functioning it is assumed that reuptake removes $90 \%$ of the serotonin in the extracellular compartment and that diffusion removes the remaining $10 \%$. Genetic variation in serotonin transporter (SERT) function is assumed to reduce the reuptake percentage. The rate of diffusion is assumed to be constant.

\section{Extracellular 5-HT}

Serotonin enters the extracellular compartment by way of vesicular release and is removed actively by reuptake and passively by diffusion. The dynamics of extracellular 5-HT $(Y)$ is characterized by

$$
\mathrm{d} Y / \mathrm{d} t=\rho-(v Y+\delta Y)
$$

where $Y$ denotes the amount of 5-HT in the extracellular compartment, $\rho$ represents the rate at which 5-HT added to the extracellular compartment (e.g., via vesicular release), and $v$ represents the rate at which 5-HT is removed from the extracellular compartment via reuptake, and where $\delta$ represents rate of diffusion.

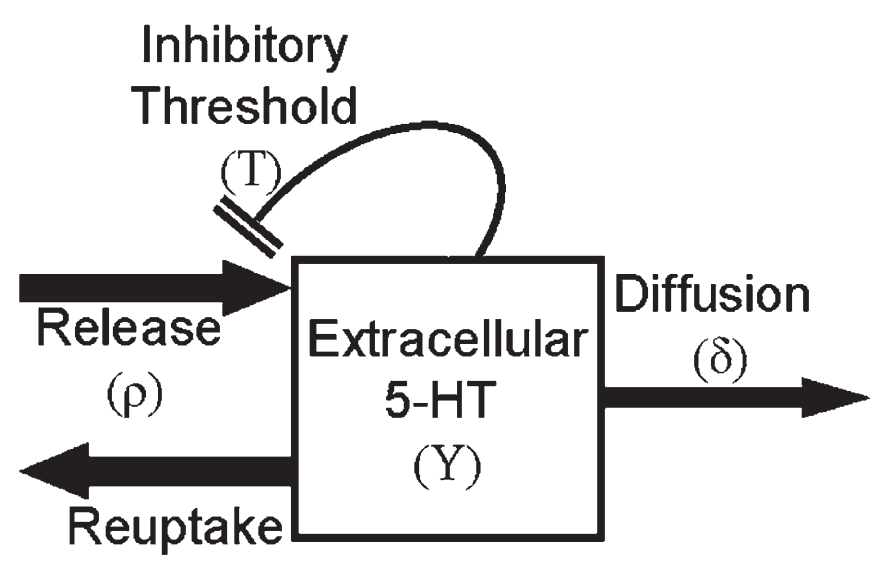

(v)

Figure 1. Dynamic model of presynaptic 5-HT system regulation: $Y$ denotes extracellular 5-HT level, $\rho$ denotes the release rate, $v$ denotes the reuptake rate, $\delta$ denotes the diffusion rate and $T$ denotes the inhibitory threshold. See text for a detailed explanation of the model and for equations.

\section{Somatodendritic Autoreceptor}

When the level of 5-HT in the extracellular compartment exceeds an inhibitory threshold somatodendritic autoreceptors (i.e., 5- $\mathrm{HT}_{1 \mathrm{~A}}$ ) inhibit neural firing. In this simulation, it is assumed that $5-\mathrm{HT}_{1 \mathrm{~A}}$ autoreceptors dynamically adjust their inhibitory thresholds such that 5-HT neurons maintain a characteristic, regular firing rate across a range of extracellular 5-HT levels. The dynamic inhibitory threshold in this negative feedback loop is characterized by

$$
d T / d=T+\mathrm{A}
$$

where $T$ denotes the inhibitory threshold (in 5-HT units) and A represents a conditional adjustment factor, based on whether the system "fired" (i.e., released 5-HT). The equation for the adjustment factor is characterized by

$$
\mathrm{A}(t)= \begin{cases}\kappa & \text { if } \rho=0 \\ \lambda & \text { if } \rho>0\end{cases}
$$

where $\kappa>0$, that is, $\kappa$ increases the inhibitory threshold, making it more likely that the system will fire at the next time step; and $\lambda<0$, that is, $\lambda$ decreases the inhibitory threshold, making it less likely that the system will fire at the next time step. 
We defined the inhibitory threshold $(T)$ as the amount of extracellular 5-HT above which presynaptic 5-HT neural firing is inhibited. That is, $T$ represents the sensitivity of somatodendritic autoreceptors. Initial $T$ values are set below the level of the average release value because it was reasoned that firing should be inhibited if the amount of neurotransmitter remaining in the extracellular space was equal to or greater than the average release amount. This assumes that for proper neurotransmission a substantial amount of neurotransmitter must be cleared from the extracellular space before another firing event is permitted to occur.

\section{Terminal Autoreceptor}

Terminal autoreceptors (i.e., 5- $\mathrm{HT}_{1 \mathrm{~B}}$ ) influence the amount of 5-HT released per release event. In this model the amount of 5-HT to be released is a function of a constant baseline release value (B) that is corrected with respect to the amount of 5-HT in the extracellular compartment (i.e., is inversely proportional to). Therefore, terminal autoreceptor regulation of release is characterized by

$$
\rho=\left[\left(\frac{B}{Y+1}\right) \otimes C\right]
$$

where B represents a constant release value (50) and $Y$ denotes amount of 5-HT in the extracellular compartment. To avoid having a zero in the denominator, $Y+1$ is used. To achieve reasonable release values a correction factor is used, where $C$ is a constant (100).

\section{Outcome Measures}

Level of extracellular 5-HT was an outcome variable of primary interest. For each simulation run the initial starting level of extracellular 5-HT (i.e., $\left.Y_{(0)}\right)$ was set at 50. Parameter plots that varied the initial level of 5-HT from 0 to 500 had no effect on outcome variables. Parameter plots that varied the initial inhibitory threshold (T) from 0 to 500 had no effect on EXSER, but increased SERFIRE Rate (ratio of times fired to time steps) linearly from 0.49 to 0.59 (data not shown). The initial value for $T$ (50) was chosen so that at baseline the system maintained a regular firing rate (around 0.50) and with tight regular oscillations around the inhibitory threshold, and because it was assumed that the initial inhibitory threshold should be below the average release value so that if most of the 5- HT from a single release remained in the synapse the system would be inhibited firing at the next time step. The exact value of $T_{\text {(initial) }}=50$ was arbitrary.

The other outcome variable of primary interest was "Firing Rate" defined as the number of times that the system fired (i.e., released 5-HT) divided by the number of time steps. For each model condition, extracellular 5-HT Level and firing rate were recorded after 50,000 time steps. Because randomness was not built into the model, one run for each condition was sufficient to produce outcomes that may be considered the true values of those indices (i.e., additional runs under the same conditions produced identical values).

\section{Model Verification}

To verify that the model is doing what is expected, the following approach was taken. First, parameter plots were generated for each outcome variable across ranges of an independent variable (e.g., reuptake rate) and these were inspected for conceptual coherence. Next, the baseline outcomes for the model were established by performing a run of 50,000 time steps. Then for each of the parameters of interest (SERT [S], $\left.5-\mathrm{HT}_{1 \mathrm{~A}}[\mathrm{~A}] ; 5-\mathrm{HT}_{1 \mathrm{~B}}[\mathrm{~B}]\right)$ we set each to simulate a loss of function due to genetic deletion (i.e., knockout, see Table I). Results were compared to those in the empirical literature with respect to direction and magnitude of effect.

\section{Data Analysis and Statistics}

The effects of manipulating reuptake rate (i.e., SERT $\mathrm{KO}), 5-\mathrm{HT}_{1 \mathrm{~A}}$ somatodendritic autoreceptor function (i.e., $5-\mathrm{HT}_{1 \mathrm{~A}} \mathrm{KO}$ ) and $5-\mathrm{HT}_{1 \mathrm{~B}}$ terminal autoreceptor function (i.e., $5-\mathrm{HT}_{1 \mathrm{~B}} \mathrm{KO}$ ) on simulated extracellular 5 -HT level and firing rate were examined. The effect

Table I. Model parameters.

\begin{tabular}{lllll}
\hline Knockout & Genotype & Variable & $\begin{array}{l}\text { Baseline } \\
\text { value }\end{array}$ & $\begin{array}{l}\text { KO } \\
\text { value }\end{array}$ \\
\hline SERT & S-/A+/B+ & $\begin{array}{l}\text { Reuptake } \\
\text { rate }(v)\end{array}$ & 0.90 & 0.00 \\
$5-\mathrm{HT}_{1 \mathrm{~A}}$ & $\mathrm{~S}+/ \mathrm{A}-/ \mathrm{B}+$ & $\begin{array}{l}\text { Threshold } \\
\text { adjustment }(\lambda)\end{array}$ & -5 & -1 \\
5-HT & $\mathrm{S}+/ \mathrm{A}+/ \mathrm{B}-\mathrm{B}+1) \ddot{\mathrm{A} C} \mathrm{C}]$ & 100 \\
\hline
\end{tabular}

$\mathrm{B}$ represents a release constant, set at 50 , and $C$ represents an adjustment factor set at 100. $Y$ represents the amount of 5-HT detected in the extracellular compartment. 


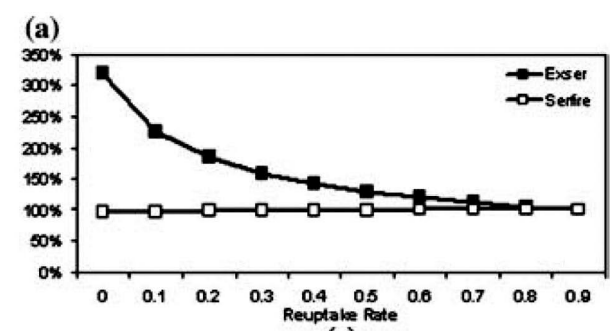

(v)

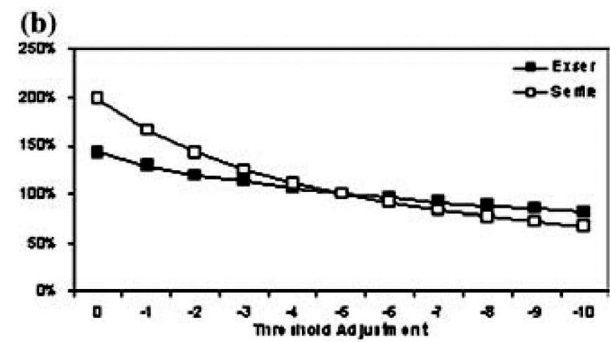

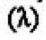

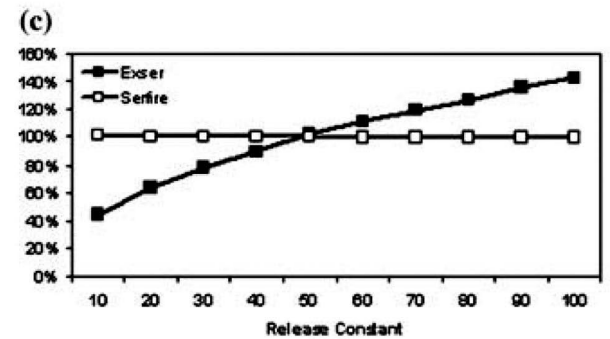

(B)

Figure 2. Parameter plots generated by varying one parameter while holding others at baseline level. Each graph shows curves for extracellular 5-HT level (Exser, black square) and presynaptic system firing rate (Serfire, white square). Baseline level was set to $100 \%$. Parameter plots are shown for (a) reuptake rate simulating variation in 5-HT transporter function, (b) threshold adjustment simulating variation in $5-\mathrm{HT}_{1 \mathrm{~A}}$ somatodendritic autoreceptor function, (c) release constant simulating variation in $5-\mathrm{HT}_{1 \mathrm{~B}}$ terminal autoreceptor function.

of each simulated condition was examined independently, as well as in logical combinations with the other conditions (i.e., double and triple knockouts). For statistical analyses, raw data were used. The Mann-Whitney test used to examine single gene effects. Although the outcome measures are accurate population parameters, assessing the effect of knocking out a single gene in this study required the comparison of two groups, each with $N=4$. Rank order methods seemed preferable to parametric methods for such comparisons. For the multiple knockout conditions, visual inspection of histograms was used to assess epistatic interactions. Interactions were not formally tested because of concerns regarding the power of non-parametric statistical tests to detect interactions when the total $N=8$. However, because the outcome values can be considered population parameters (i.e., no uncertainty) it seemed reasonable to assess interaction through visual inspection of the output in line figures. Departures from parallel indicate the presence of interaction. For the Figures, the baseline extracellular 5-HT level (Exser) and firing rate (Serfire) were set to $100 \%$ and knockout values are shown relative to baseline.

\section{Results}

\section{Parameter Plots}

Parameter plots were generated to assess change in level of extracellular 5-HT (Exser) and system firing rate (Serfire) across the range of a single parameter (see Figure 2).

Varying the reuptake rate had no substantial effect on Serfire, but did affect Exser (see Figure 2a). Reducing reuptake is known to increase extracellular levels of 5-HT and temporarily reduces firing rate. Down regulation or desensitization of somatodendritic autoreceptors $\left(5-\mathrm{HT}_{1 \mathrm{~A}}\right)$ allows neural firing at higher levels of extracellular 5-HT and this dynamic model captures this adaptation as shown by the high levels of Exser at low uptake rates and firing rates that are little changed relative to baseline.

The threshold adjustment $\lambda$ represents antagonism of the $5-\mathrm{HT}_{1 \mathrm{~A}}$ autoreceptor that inhibits firing when activated, therefore, blocking an inhibitory function would raise the inhibitory threshold (i.e., allowing the system to fire at elevated levels of extracellular 5-HT). Reducing $\lambda$ permits system firing at higher Exser levels thereby resulting in higher Exser levels and higher rates of firing [see Figure 2(b)]. Recall that $\kappa$ raises the inhibitory threshold, while $\lambda$ lowers it. When $\kappa$ $>\lambda$, the inhibitory threshold rises faster than it falls, which results in higher levels of the inhibitory threshold overall.

Varying the release constant (B) has no effect on Serfire, but is positively associated with Exser (see Figure 2c). It is logical that higher rates of release will increase Exser levels when all other variables remain constant.

The behavior of the model, as shown in these parameter plots, is consistent with expectations, thereby achieving a basic level of model verification (Rykiel, 1996).

\section{Baseline Levels}

Running the model with the baseline values given in Table I produced an extracellular 5-HT level of 
49.38 units, and a firing rate of 0.50 (i.e., 25,000 firings $/ 50,000$ time steps). The raw values were then set to $100 \%$ to facilitate visual comparisons with the simulated knockout conditions.

\section{Knockouts}

To examine the effect of genetic deletion of components in this minimal model of presynaptic 5- HT function, baseline values were systematically replaced with the knockout values shown in Table I to simulate seven knockout conditions (three single, three double, and one triple knockout). For the analysis of single gene effects, the Mann-Whitney test was used (Table II).

\section{Single Knockouts}

For Exser, the main effect of SERT knockout was significant, $U=0.00, p=.02$. Mean Exser rank for the SERT knockout conditions (S- $=6.5$ ) was higher than mean Exser for the functional SERT conditions $(\mathrm{S}+=2.5)$. For Serfire, the main effect of SERT knockout was not significant, $U=4.0, p=.25$. Mean Serfire rank for the SERT knockout conditions was (S- = 3.5) and for the functional SERT conditions it was ( $++=$ 5.5). Consistent with the parameter plot results, reducing reuptake rate (i.e., knockout out SERT function) increased levels of extracellular 5-HT and produced essentially no change in firing rates. Firing inhibition is initially observed in the SERT knockout condition (data not shown). However, because the inhibitory threshold dynamically responds to changes in 5-HT levels, the firing rates after 50,000 time steps are not significantly reduced relative to non-knockout conditions.

For Exser, the main effect of $5-\mathrm{HT}_{1 \mathrm{~A}}$ knockout was not significant, $U=5.00, p=.39$. Mean Exser rank for the $5-\mathrm{HT}_{1 \mathrm{~A}}$ knockout conditions was $(\mathrm{A}-=5.25)$ and for the functional 5- $\mathrm{HT}_{1 \mathrm{~A}}$ conditions it was $(\mathrm{A}+=$ 3.75). For Serfire, the main effect of $5-\mathrm{HT}_{1 \mathrm{~A}}$ knockout was significant $U=0.00, p=.02$. Mean Serfire rank for the 5- $\mathrm{HT}_{1 \mathrm{~A}}$ knockout conditions $(\mathrm{A}-=6.5$ ) was higher than mean Serfire rank for the functional 5$\mathrm{HT}_{1 \mathrm{~A}}$ conditions $(\mathrm{A}+=2.5)$.

For Exser, the main effect of $5-\mathrm{HT}_{1 \mathrm{~B}}$ knockout was not significant, $U=5.00, p=.34$. Mean Exser rank for the $5-\mathrm{HT}_{1 \mathrm{~B}}$ knockout conditions was $(\mathrm{B}-=5.25)$ and for the functional $5-\mathrm{HT}_{1 \mathrm{~B}}$ conditions it was $(\mathrm{B}+=$ 3.75). For Serfire, the main effect of $5-\mathrm{HT}_{1 \mathrm{~B}}$ knockout was not significant $U=6.5, p=.66$. Mean Serfire rank for the $5-\mathrm{HT}_{1 \mathrm{~B}}$ knockout conditions was (B- = 4.13) and for the functional $5-\mathrm{HT}_{1 \mathrm{~B}}$ conditions it was $(\mathrm{B}+=$ $4.88)$.

\section{Multiple Knockouts}

In order to identify potential gene-gene interactions on the level of extracellular 5-HT (Exser) the results of simulation runs are shown in Figure 3. Results for the wild type (+) and knockout (-) alleles for both the $5-\mathrm{HT}_{1 \mathrm{~A}}(\mathrm{~A})$ and $5-\mathrm{HT}_{1 \mathrm{~B}}(\mathrm{~B})$ autoreceptors are shown in combination and grouped by SERT (S) genotype. The values shown are relative to the baseline $(\mathrm{S}+/ \mathrm{A}+/ \mathrm{B}+)$ condition, which is set to $100 \%$. Little variation is seen across $\mathrm{A}$ and $\mathrm{B}$ genotypes in the S+ condition. However, in the S- condition, substantial increases in Exser

Table II. Effects of genetic deletion or pharmacological agents on 5-HT level and 5-HT cell firing rates in empirical literature.

\begin{tabular}{|c|c|c|c|c|}
\hline Knockout & Genotype & $\begin{array}{l}\text { 5-HT } \\
\text { Level }\end{array}$ & $\begin{array}{c}\text { Firing } \\
\text { rate }\end{array}$ & Citation \\
\hline \multirow[t]{3}{*}{ Single } & $\mathrm{S}-/ \mathrm{A}+/ \mathrm{B}+$ & $\uparrow \uparrow$ & $\downarrow / 0$ & $\begin{array}{l}\text { de Groote et al., (2002), } \\
\text { Evrard et al., (2002), } \\
\text { Gobbi et al., (2001), } \\
\text { Knobelman et al., (2001b), } \\
\text { Malagie et al., (2002) and } \\
\text { Mannoury la Cour et al., (2001) }\end{array}$ \\
\hline & $\mathrm{S}+/ \mathrm{A}-/ \mathrm{B}+$ & $0 / \uparrow$ & $\uparrow$ & $\begin{array}{l}\text { He et al., (2001), } \\
\text { Knobelman et al., (2001), } \\
\text { Parsons et al., (2001) and } \\
\text { Richer et al., } 2002\end{array}$ \\
\hline & $\mathrm{S}+/ \mathrm{A}+/ \mathrm{B}-$ & 0 & $0 / \downarrow$ & $\begin{array}{l}\text { de Groote } \text { et al., (2002), } \\
\text { Evrard et al., (1999), } \\
\text { Knobelman et al., (2001) }\end{array}$ \\
\hline \multirow[t]{3}{*}{ Double } & $\mathrm{S}-/ \mathrm{A}-/ \mathrm{B}+$ & $\uparrow \uparrow \uparrow$ & $\uparrow$ & $\begin{array}{l}\text { Gobbi et al., (2001), } \\
\text { He et al., (2001), } \\
\text { Knobelman et al., (2001), } \\
\text { Knobelman et al., (2001), } \\
\text { Parsons et al., (2001) }\end{array}$ \\
\hline & $\mathrm{S}-/ \mathrm{A}+/ \mathrm{B}-$ & $\uparrow \uparrow \uparrow$ & $\downarrow / 0$ & $\begin{array}{l}\text { de Groote } \text { et al., (2002), } \\
\text { Evrard et al., (1999), } \\
\text { Knobelman et al., (2001), } \\
\text { Knobelman et al., (2001), } \\
\text { Malagie et al., (2002) }\end{array}$ \\
\hline & $\mathrm{S}+/ \mathrm{A}-/ \mathrm{B}-$ & $?$ & $?$ & None \\
\hline Triple & S-/A-/B- & $\uparrow \uparrow \uparrow$ & $?$ & Knobelman et al., (2001) \\
\hline
\end{tabular}

S- $=$ SERT KO, A- $=5-\mathrm{HT}_{1 \mathrm{~A}} \mathrm{KO}, \mathrm{B}-=5-\mathrm{HT}_{1 \mathrm{~B}} \mathrm{KO}$. Increases are indicated by arrows: $100-200 \%=\uparrow, 200-600 \%=\uparrow \uparrow$, over $600 \%=\uparrow \uparrow \uparrow$; Decreases are indicated by $\downarrow$. No change is indicated by 0 . No report in literature $=$ ?. When no knockout data was available in the literature, data from pharmacological challenge studies was used (most often in double and triple knockout conditions). 


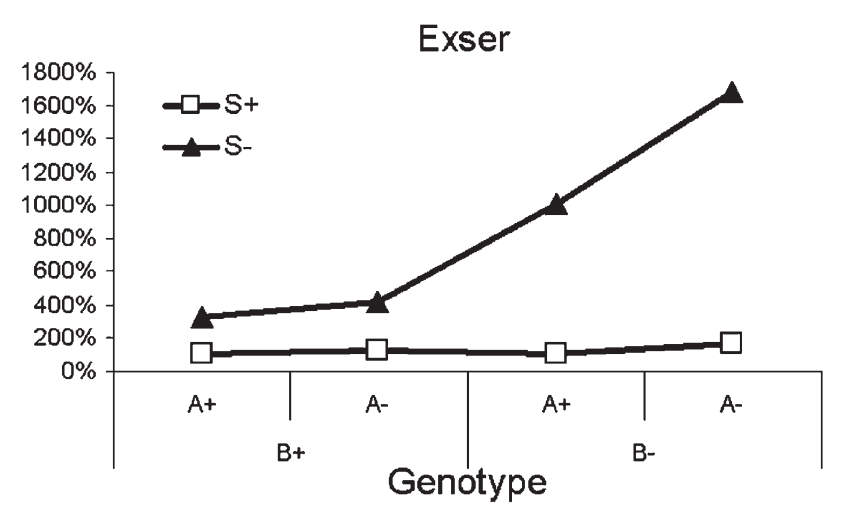

Figure 3. Simulated levels of extracellular 5-HT for conditions defined by 5 - $\mathrm{HT}$ transporter $(\mathrm{S}), 5-\mathrm{HT}_{1 \mathrm{~B}}(\mathrm{~B})$ and $5-\mathrm{HT}_{1 \mathrm{~A}}$ (A) genotypes. The wild-type state is indicated by $(+)$ and the knockout state is indicated by $(-)$. Baseline $(\mathrm{S}+/ \mathrm{B}+/ \mathrm{A}+)$ is set to $100 \%$. Differences in the pattern of B/A genotype effects across $S$ genotype groups are evidence of epistatic interaction among components for extracellular 5-HT level.

are observed such that knocking out A and B augments the Exser increase seen in the $\mathrm{S}$ knockout, and the triple knockout produces the highest observed Exser levels. Different patterns of results between the $\mathrm{S}+$ and S- groups suggest that epistatic interactions among SERT and the 1A and $1 \mathrm{~B}$ autoreceptors influence extracellular 5-HT levels.

In order to identify potential gene-gene interactions on firing rate (Serfire) the results of simulation runs are shown in Figure 4 . Results of the $S$ and B knockout conditions are grouped by A genotype. The two lines are parallel which suggests that that SERT and the $1 \mathrm{~A}$ and $1 \mathrm{~B}$ autoreceptors do not interact to influence rates of 5-HT neural firing.

\section{Discussion}

The main finding of the present study is that an oversimplified, top down, dynamic model of 5- HT system regulation reproduced important aspects of 5HT function, and that simulation results suggest that epistasis among system components may influence aspects of system function, specifically extracellular 5-HT level. The simulation results were largely consistent with recent empirical results from microdialysis and electrophysiological studies in mice. Reducing clearance rates, which in the model simulates the reduction of SERT function by genetic deletion, raised extracellular 5-HT levels. Knocking out the 5- $\mathrm{HT}_{1 \mathrm{~A}}$ and/or $5-\mathrm{HT}_{1 \mathrm{~B}}$ autoreceptors in the SERT knockout augmented the observed increase in extracellular 5-HT that resulted from reducing SERT mediated

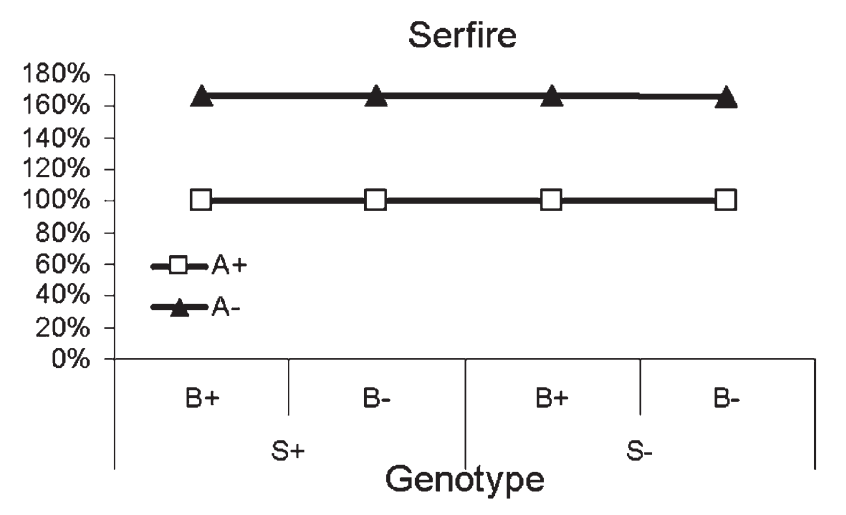

Figure 4. Simulated rates of presynaptic 5-HT firing for conditions defined by $5-\mathrm{HT}$ transporter $(\mathrm{S}), 5-\mathrm{HT}_{1 \mathrm{~B}}(\mathrm{~B})$ and $5-\mathrm{HT}_{1 \mathrm{~A}}$ (A) genotypes. The wild-type state is indicated by $(+)$ and the knockout state is indicated by $(-)$. Baseline $(\mathrm{A}+/ \mathrm{S}+/ \mathrm{B}+)$ is set to $100 \%$. Parallel lines across A genotype groups indicates that there is no epistatic interaction among components for firing rate.

clearance rates alone. The highest levels of extracellular 5-HT were achieved in the triple knockout condition. Knocking out the function of the $5 \mathrm{HT}_{1 \mathrm{~A}}$ somatodendritic autoreceptor in the simulation produced higher system firing rates, but did not substantially affect levels of extracellular 5-HT. Knocking out the only function of the $5-\mathrm{HT}_{1 \mathrm{~B}}$ terminal autoreceptor in the simulation did not affect extracellular 5-HT levels or firing rates. However, when the $5-\mathrm{HT}_{1 \mathrm{~B}}$ terminal autoreceptor was knocked out in combination with other components the resulting patterns of extracellular 5- HT level suggested significant epistatic interaction. These simulation results are consistent with the empirical literature on knockout mice.

In wild-type mice, SSRI treatment raised extracellular levels of 5-HT to $200-300 \%$ of baseline (de Groote et al., 2002; He et al. 2001; Malagie et al., 2002; Parsons et al., 2001); and extracellular 5-HT enhancement is expected, but has not been reported in SERT knockout mice. The extracellular 5-HT enhancing effects of SSRI administration were augmented in 5$\mathrm{HT}_{1 \mathrm{~A}}$ and $5-\mathrm{HT}_{1 \mathrm{~B}}$ knockout mice, relative to wild type, as well as in wild-type mice treated with a 5$\mathrm{HT}_{1 \mathrm{~A}}$ or $5-\mathrm{HT}_{1 \mathrm{~B}}$ antagonist (de Groote et al., 2002; $\mathrm{He}$ et al., 2001; Knobelman et al., 2001a, b). These same patterns of results were observed in the present simulation study, if one assumes similarity, on a gross level, of SERT KO and SSRI treatment. Both reduce 5-HT reuptake, although constitutive knockouts result in developmental effects that acute SSRI treatment do not (Salichon et al., 2001). Another difference that can be seen between constituative knockouts and 
acute SSRI treatment in the firing rate of 5-HT neurons. Complete firing inhibition can be achieved with SSRI treatment (Evrard et al., 1999, 2002), whereas genetic deletion of SERT produces 5-HT firing rates that are either no different than wild type (Mannoury la Cour et al., 2001), or somewhat reduced (Gobbi et al., 2001). Desensitization of somatodendritic $5-\mathrm{HT}_{1 \mathrm{~A}}$ autoreceptors in SERT knockouts permits firing of 5-HT neurons (Gobbi et al., 2001), and it is thought that this dynamic change in autoreceptor sensitivity may underlie the therapeutic delay observed in SSRI treatment for depression, though the exact mechanism is not completely characterized (Hensler, 2002).

Simulation results showed a modest increase in 5HT level in the $5-\mathrm{HT}_{1 \mathrm{~A}} \mathrm{KO}$ condition $(129 \%$ of baseline value), in contrast to the results of several empirical studies where extracellular 5-HT levels in 5- $\mathrm{HT}_{1 \mathrm{~A}}$ knockout mice are not different from that observed in wild-type mice (de Groote et al., 2002; Evrard et al., 2002; He et al., 2001; Knobelman et al., 2001b; Richer et al., 2002), although a modest increase in extracellular 5-HT was reported in one study Parsons et al., 2001). It may be that this discrepancy is a signal that there is some misspecification in the theoretical model underlying the simulation (e.g., lack of a relevant adaptation mechanism or less than optimal parameter values) or to differences in extracellular 5-HT level that are below the threshold of detection of the microdialysis techniques used. It is also possible that epistatic interactions among $5-\mathrm{HT}_{1 \mathrm{~A}}$ mutant alleles and one or more unmeasured background alleles might mask the effect of the genetic deletion Palmer et al., 2003).

There are some limitations of the simulation that should be considered. Expression or functional differences among different brain regions in terminal autoreceptors (Fabre et al., 2000; Knobelman et al., 2001a, b; Malagie et al., 2002), somatodendritic autoreceptors (Fabre et al., 2000; Knobelman et al., 2001a, b; Mannoury la Cour et al., 2001), or transporters Montanez et al., 2002) were not considered in this simulation. The model also did not address 5-HT synthesis, metabolism or post-synaptic effects. However, given that the simulation produced output with a high degree of consistency with empirical observations, such shortfalls do not appear to detract from the potential usefulness of the model for understanding global aspects of 5-HT regulation.

The relation of the time steps in the model to real time units is not immediately obvious. Microdialysis and single-unit recording measurements are usually performed on quite different time scales and not simultaneously in the same animal. In the simulation, the first few time steps (approximately 20 or 30) capture the firing inhibition mediated by the $5-\mathrm{HT}_{1 \mathrm{~A}}$ autoreceptors; whereas the values reported in this study are those observed at time step 50,000 well after dynamic adjustments to the inhibitory threshold have taken place (i.e., equilibrium has been established). Run time parameters in the present model could be optimized to fit particular time scales, however, it seems that the real contribution of this model is to provide a flexible platform for thinking about and generating hypotheses about the relations among system parameters and outcomes.

Comparing the simulation results to empirical results from the literature identifies several instances where directional hypotheses can be made to fill in gaps in the empirical literature. We were unable to identify empirical data for comparison to the results for 5-HT firing rates in $5-\mathrm{HT}_{1 \mathrm{~A}}$ and $5-\mathrm{HT}_{1 \mathrm{~B}}$ double knockouts, but the simulation results suggest that the firing rates of 5-HT neurons would be elevated (167\%) as would levels of extracellular 5-HT (169\%) relative to wild type. In a triple $\mathrm{KO}$ mouse, results from the simulation predict that firing rates of 5-HT neurons would be elevated $(167 \%)$ relative to wild type. In each of these cases, the simulation results can serve as directional hypotheses to be tested with microdialysis or electrophysiology studies in mice. Such studies will further test the validity of the present model of presynaptic 5-HT regulation. Generation of testable hypotheses is an important aspect of simulation (Gallaher, 1996). This model of 5-HT function could also be used to simulate human genetic variation by using less extreme parameter values than were used here to simulation genetic deletion (Montanez et al., 2003). The simulation could also be used to examine the effects of pharmacological agents that act at the three presynaptic 5-HT components examined in the model. In an extension to the model, we examined the effects of a common SERT promoter variant (5-HTTLPR) on 5-HT and dopaminergic function in the context of pharmacological treatment for alcoholism (Stoltenberg, 2003). Other extensions of this model are being planned to address some of its current shortcomings, including the addition of an early life stress variable, because of the important of early life stress in 5-HT function and in traits influenced by 5-HT (Caspi et al., 2003; Huizink et al., 2004; Vazquez et al., 2002). 
How does this modeling approach fit into the larger context of theoretical neuroscience? Neuroscientists have been using computational models to study aspects of brain function since the mid twentieth century. Broadly, the areas of investigation can be lumped into two categories: single cells and networks (for an excellent overview of the field see the Nature Neuroscience Supplement Volume 3, November 2000). Decades of progress in computational neuroscience has resulted in exquisitely sophisticated biophysical models of neural firing (bottom-up) and network models of cognition (top-down). However, little emphasis has been placed on understanding the role of genetic variation in producing differences in the functioning of neural systems. The present model lies somewhere in between models of single neurons and neural networks and utilizes a dynamic systems approach that has a long history in its own right and has been used to study the workings of the brain (von Bertalanffy, 1968; Wiener, 1961). The hope is that by using computational techniques we can arrive at a better understanding of how heredity influences behavior.

How important is it to understand epistatic interaction in the 5-HT system? If epistasis is a fundamental feature of 5-HT functioning, then the genetic architectures for the myriad psychiatric disorders associated with 5-HT dysfunction must include genegene interactions. Traditional approaches to identify genes underlying single gene disorders may not be suitable to identify genes in the presence of epistasis, which may explain some of the difficulty in identifying genes for psychiatric disorders (Williams et al., 2004). If epistasis is ubiquitous in common human diseases (Moore, 2003), new approaches will be required to study their etiology.

\section{Conclusion}

This simulation of 5-HT regulation captures many important aspects of 5-HT function including epistasis. Epistatic interaction among presynaptic system components appears to be an important feature of the 5HT system's regulation of 5-HT levels, and therefore should be considered in studies that seek to understand the influence of 5-HT system genetics on behavior. The use of simulations should enable hypothesis generation and help to crystallize our understanding of an important neurotransmitter system.

\section{Appendix 1}

\section{Berkeley-Madonna 8.0.1 Code for Epistasis Model}

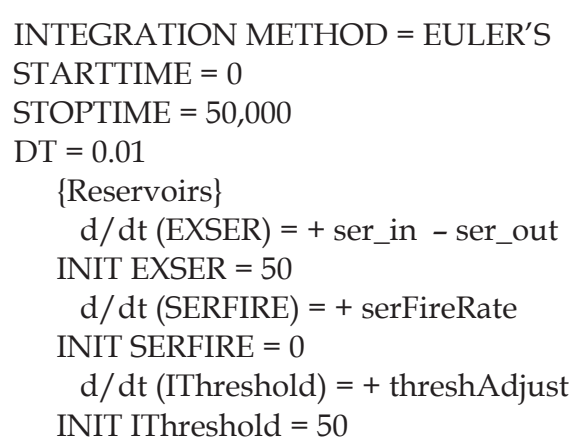

Flows

ser_in $=$ IF EXSER $>$ IThreshold THEN 0 ELSE R

ser_out $=($ REUPTAKE_RATE*EXSER $)+$

(DIFFUSION*EXSER)

serFireRate $=$ IF ser_in $>0$ THEN 1 ELSE 0

threshAdjust $=$ IF serFireRate $=0$ THEN AU ELSE AD

\{Functions

$\mathrm{AU}=5$

$\mathrm{R}=\mathrm{IF}$ HT1B= 1 THEN $(\mathrm{B} /(\mathrm{EXSER}+1))^{* 100} \operatorname{ELSE}(2 * \mathrm{~B})$

$\mathrm{B}=50$

REUPTAKE_RATE $=0.90$

DIFFUSION $=0.1$

$\mathrm{HT} 1 \mathrm{~B}=1$

$\mathrm{AD}=-5$

\section{Acknowledgments}

This work was supported by a NIAAA Career Development Award (K01 AA00295). Thanks to Ed Cook, Julie Hensler, Rick Riolo, Srijan Sen, and anonymous reviewers for Behavior Genetics for thoughtful comments on earlier versions of this manuscript; and to Ed Gallaher for introducing me to system dynamics modeling and for his comments on the model.

\section{References}

Aghajanian, G. K., and Marek, G. J. (2000). Serotonin model of schizophrenia: Emerging role of glutamate mechanisms. Brain Res. Brain Res. Rev. 31:302-312.

Aghajanian, G. K., and Sanders-Bush, E. (2002). Serotonin. In K. L. Davis, D. S. Charney, J. T. Coyle, and C. Nemeroff (eds.), Neuropsychopharmacology: The fifth generation of progress. Philadelphia, PA: The American College of Neuropsychopharmacology, pp. 15-34.

Baumgarten, H., and Gothert, M. (1999). Serotonergic neurons and 5-HT receptors in the CNS. Springer Verlag.

Baumgarten, H. G., and Grozdanovic, Z. (1998). Role of serotonin in obsessive-compulsive disorder. Br. J. Psychiatry Suppl.: 13-20. 
Blier, P., and de Montigny, C. (1998). Possible serotonergic mechanisms underlying the antidepressant and anti-obsessive- compulsive disorder responses. Biol. Psychiatry. 44:313- 323.

Brodie, E. D. III (2000). Why evolutionary genetics does not always add up. In J. B. Wolf, E. D. Brodie III, and M. J. Wade (eds.), Epistasis and the evolutionary process. New York: Oxford University Press, pp. 3-19.

Caspi, A., Sugden, K., Moffitt, T. E., Taylor, A., Craig, I. W., Harrington, H., McClay, J., Mill, J., Martin, J., Braithwaite, A., and Poulton, R. (2003). Influence of life stress on depression: moderation by a polymorphism in the 5-HTT gene. Science 301:386-389.

de Groote, L., Olivier, B., and Westenberg, H. G. (2002). Extracellular serotonin in the prefrontal cortex is limited through terminal 5-HT(1B) autoreceptors: a microdialysis study in knockout mice. Psychopharmacology (Berlin) 162:419-424.

Evrard, A., Laporte, A. M., Chastanet, M., Hen, R., Hamon, M., and Adrien, J. (1999). 5-HT1A and 5-HT1B receptors control the firing of serotoninergic neurons in the dorsal raphe nucleus of the mouse: studies in 5-HT1B knock-out mice. Eur. J. Neurosci. 11:3823-3831.

Evrard, A., Malagie, I., Laporte, A. M., Boni, C., Hanoun, N., Trillat, A. C., Seif, I., De Maeyer, E., Gardier, A., Hamon, M., and Adrien, J. (2002). Altered regulation of the 5-HT system in the brain of MAO-A knock-out mice. Eur. J. Neurosci. 15:841-851.

Fabre, V., Beaufour, C., Evrard, A., Rioux, A., Hanoun, N., Lesch, K. P., Murphy, D. L., Lanfumey, L., Hamon, M., and Martres, M. P. (2000). Altered expression and functions of serotonin 5-HT1A and 5-HT1B receptors in knockout mice lacking the 5-HT transporter. Eur. J. Neurosci. 12:2299-2310.

Gallaher, E. J. (1996). Biological system dynamics: From personal discovery to universal application. Simulation 66:243-257.

Gobbi, G., Murphy, D. L., Lesch, K., and Blier, P. (2001). Modifications of the serotonergic system in mice lacking serotonin transporters: An in vivo electrophysiological study. J. Pharmacol. Exp. Ther. 296:987-995.

He, M., Sibille, E., Benjamin, D., Toth, M., and Shippenberg, T. (2001). Differential effects of 5-HT(1A) receptor deletion upon basal and fluoxetine-evoked 5-HT concentrations as revealed by in vivo microdialysis. Brain Res. 902:11-17.

Heinz, A., Mann, K., Weinberger, D. R., and Goldman, D. (2001). Serotonergic dysfunction, negative mood states, and response to alcohol. Alcohol Clin. Exp. Res. 25:487- 495.

Hensler, J. G. (2002). Differential regulation of 5-HT1A receptor-G protein interactions in brain following chronic antidepressant administration. Neuropsychopharmacology 26:565-573.

Hill, E. M., Stoltenberg, S. F., Burmeister, M., Closser, M., and Zucker, R. A. (1999). Potential associations among genetic markers in the serotonergic system and the antisocial alcoholism subtype. Exp. Clin. Psychopharmacol. 7:103-121.
Huizink, A. C., Mulder, E. J., and Buitelaar, J. K. (2004). Prenatal stress and risk for psychopathology: Specific effects or induction of general susceptibility? Psychol. Bull. 130:115-142.

Knobelman, D. A., Hen, R., Blendy, J. A., and Lucki, I. (2001a). Regional patterns of compensation following genetic deletion of either 5-hydroxytryptamine(1A) or 5-hydroxytryptamine( 1B) receptor in the mouse. J. Pharmacol. Exp. Ther. 298:1092-1100.

Knobelman, D. A., Hen, R., and Lucki, I. (2001b). Genetic regulation of extracellular serotonin by 5hydroxytryptamine(1A) and 5-hydroxytryptamine(1B) autoreceptors in different brain regions of the mouse. J. Pharmacol. Exp. Ther. 298:1083-1091.

Lesch, K. P., Benninghoff, J., and Schmitt, A. (2002). The psychopharmacogenetic- neurodevelopmental interface in serotonergic gene pathways. In B. Lerer (ed.), Pharmacogenetics of psychotropic drugs. Cambridge: Cambridge University Press.

Malagie, I., David, D. J., Jolliet, P., Hen, R., Bourin, M., and Gardier, A. M. (2002). Improved efficacy of fluoxetine in increasing hippocampal 5-hydroxytryptamine outflow in 5-HT(1B) receptor knock-out mice. Eur. J. Pharmacol. 443:99-104.

Mannoury la Cour, C., Boni, C., Hanoun, N., Lesch, K. P., Hamon, M., and Lanfumey, L. (2001). Functional consequences of 5-HT transporter gene disruption on 5-HT(1a) receptor-mediated regulation of dorsal raphe and hippocampal cell activity. J. Neurosci. 21:2178-2185.

Montanez, S., Daws, L. C., Gould, G. G., Gerhardt, G. A., and Frazer, A. (2002). Differential in vivo clearance of serotonin in rat dorsal raphe nucleus and CA3 region. Brain Res. 955:236-244.

Montanez, S., Owens, W. A., Gould, G. G., Murphy, D. L., and Daws, L. C. (2003). Exaggerated effect of fluvoxamine in heterozygote serotonin transporter knockout mice. J. Neurochem. 86:210-219.

Moore, J. H. (2003). The ubiquitous nature of epistasis in determining susceptibility to common human diseases. Hum. Hered. 56:73-82.

Murphy, D. L., Li, Q., Engel, S., Wichems, C., Andrews, A., Lesch, K. P., and Uhl, G. (2001). Genetic perspectives on the serotonin transporter. Brain Res. Bull. 56:487-494.

Palmer, A. A., Low, M. J., Grandy, D. K., and Phillips, T. J. (2003). Effects of a Drd2 deletion mutation on ethanol-induced locomotor stimulation and sensitization suggest a role for epistasis. Behav. Genet. 33:311-324.

Parsons, L. H., Kerr, T. M., and Tecott, L. H. (2001). 5-HT(1A) receptor mutant mice exhibit enhanced tonic, stress-induced and fluoxetine-induced serotonergic neurotransmission. J. Neurochem. 77:607-617.

Richer, M., Hen, R., and Blier, P. (2002). Modification of serotonin neuron properties in mice lacking 5-HT1A receptors. Eur. J. Pharmacol. 435:195-203.

Rykiel, E. J. J. (1996). Testing ecological models: the meaning of validation. Ecol. Model. 90:229-244. 
Salichon, N., Gaspar, P., Upton, A. L., Picaud, S., Hanoun, N., Hamon, M., De Maeyer, E., Murphy, D. L., Mossner, R., Lesch, K. P., Hen, R., and Seif, I. (2001). Excessive activation of serotonin (5-HT) 1B receptors disrupts the formation of sensory maps in monoamine oxidase a and 5-ht transporter knock-out mice. J. Neurosci. 21:884-896.

Stoltenberg, S. F. (2003). Serotonergic agents and alcoholism treatment: A simulation. Alcohol Clin. Exp. Res. 27:1853- 1859 .

Templeton, A. R. (2000). Epistasis and complex traits. In J. B. Wolf, E. D. Brodie III, and M. J. Wade (eds.), Epistasis and the evolutionary process. New York: Oxford University Press.

Vazquez, D. M., Eskandari, R., Zimmer, C. A., Levine, S., and Lopez, J. F. (2002). Brain 5-HT receptor system in the stressed infant rat: Implications for vulnerability to substance abuse. Psychoneuroendocrinology 27:245-272.
Veenstra-VanderWeele, J., Anderson, G. M., and Cook, E. H. Jr. (2000). Pharmacogenetics and the serotonin system: initial studies and future directions. Eur. J. Pharmacol. 410:165181. von Bertalanffy, L. (1968). General systems theory. New York: George Braziller.

Wiener, N. (1961). Cybernetics: or control and communication in the animal and the machine. Cambridge, MA: The MIT Press.

Williams, S. M., Haines, J. L., and Moore, J. H. (2004). The use of animal models in the study of complex disease: all else is never equal or why do so many human studies fail to replicate animal findings? Bioessays 26:170-179.

Zahnley, T. (2000). Berkeley madonna. Robert Macey and George Oster. 